\title{
Association of stress and anxiety with self-care in hemodialysis patients
}

\author{
Maryam Zibaei $^{1 \oplus}$, Monir Nobahar $^{2,3,4^{*}}{ }^{(\mathbb{Q}}$, Raheb Ghorbani $^{2,5}{ }^{\circledR}$ \\ ${ }^{1}$ Semnan University of Medical Sciences, Semnan, Iran \\ ${ }^{2}$ Social Determinants of Health Research Center, Semnan University of Medical Sciences, Semnan, Iran \\ ${ }^{3}$ Nursing Care Research Center, Semnan University of Medical Sciences, Semnan, Iran \\ ${ }^{4}$ Faculty of Nursing and Midwifery, Semnan University of Medical Sciences, Semnan, Iran \\ ${ }^{5}$ Department of Epidemiology and Biostatistics, Faculty of Medicine, Semnan University of Medical Sciences, Semnan, Iran
}

\section{AR T I C L E I N F O}

Article Type:

Original

\section{Article History:}

Received: 9 May 2019

Accepted: 10 November 2019

Published online: 6 January 2020

Keywords:

Stress

Anxiety

Self-care

Hemodialysis

End-stage renal disease

Chronic renal failure

End-stage kidney disease

\begin{abstract}
A B S T R A C T
Introduction: It is generally accepted that stress and anxiety are of the most common psychiatric complications of hemodialysis. Self-care is considered as one of the health promotion behaviors. Self-care reduction increases the risk of mortality and morbidity too.

Objectives: The purpose of this study was to determine the correlation between stress and anxiety with self-care in hemodialysis patients.

Patients and Methods: The present cross-sectional study was conducted on 80 hemodialysis patients, selected by convenience sampling method. The perceived stress was measured by a perceived stress scale (PSS) questionnaire, since the anxiety assessed by the Spielberger StateTrait Anxiety Inventory (STAI), accordingly, self-care assessed by hemodialysis patients' selfcare measurement scale.

Results: In this study, no patient had poor self-care. The self-care was moderate in $75 \%$ of patients and good in $25 \%$ of patients. The anxiety was mild in $46.2 \%$ of patients, moderate in $50 \%$ and severe in $3.8 \%$. The perceived stress was low in $62.5 \%$ of patients and high in $37.5 \%$ of patients. There was a significant negative correlation between the perceived stress score and the self-care score $(P=0.001, \mathrm{r}=-0.376)$, however, no correlation was observed between anxiety and self-care score $(P=0.089, \mathrm{r}=-0.193)$.

Conclusion: The results showed that stress of hemodialysis patients had a negative effect on their self-care, while anxiety had no significant effect on self-care. Therefore, it is suggested to identify and resolve the factors affecting stress of these patients, and to conduct further research regarding this subject.
\end{abstract}

Implication for health policy/practice/research/medical education:

Stress and anxiety are the most common psychiatric complications of hemodialysis. There is a correlation between perceived stress and self-care, which can be effective in improving general health of patients.

Please cite this paper as: Zibaei M, Nobaha M, Ghorbani R. Association of stress and anxiety with self-care in hemodialysis patients. J Renal Inj Prev. 2020; 9(2): e14. doi: 10.34172/jrip.2020.14.

\section{Introduction}

Chronic renal failure $(\mathrm{CRF})$ is a pathologic process with numerous causes, resulting in a steady reduction in the number and function of nephrons, and leading to endstage renal disease (ESRD) in many cases (1). An estimated 2.6 million people worldwide were treated for ESRD (2). Although hemodialysis is a therapeutic approach to ESRD, these people face many physical, psychological and stressful factors, which cannot be controlled even with new techniques (3). Hemodialysis patients not only are faced with many physiological changes, but also suffer from many psychological stresses, each of which can disrupt their status and personality (4). According to a research, all hemodialysis patients experience at least one or more psychosocial, psychological, and physiological stresses. The highest and lowest levels of physiological stress are fatigue and itching. The most psychosocial stress relates to patients are treatment costs and travel time limitations or transfer to the hospital (5). Stress coping strategies can affect the mortality of these patients, which depend on individual experiences, social support systems, individual beliefs and access to resources (5).

Anxiety is the second most common psychological disorder among patients undergoing hemodialysis (6). 
The causes of anxiety in hemodialysis patients include loneliness of the patient during hemodialysis, hemodialysis machine alarms, insertion of needle into the fistula, and central venous catheter implantation (7). Evidence suggests that $25.2 \%$ of patients undergoing hemodialysis suffer from the anxiety disorders (8). Additionally, anxiety can increase the body metabolism, reduce the hemodialysis patient's immunity, and exacerbate the symptoms of the disease and the complications of the treatment, as well as can affect the spirit and body (9). Additionally, a study showed a significant relationship among anxiety, stress, non-adherence to the recommended regiment in hemodialysis patients and even essential therapies, which could endanger the health of hemodialysis patients and accelerate their mortality (10).

Coping with this disease, the complications of treatment and promoting the quality of life of patients with ESRD require the participation of patients in treatment and care, which can be achieved by increasing knowledge, changing attitude and achieving self-care skills (11).

Self-care is a process in the acceptance phase of physical and physiological status as an essential therapy for the improvement of pathological, psychological, emotional and social conditions (4). Failure to involvement of patient and implementation of self-care activities, causes the treatment of hemodialysis patients cannot be effective enough to achieve the desired therapeutic results. Accordingly, self-care is a learnable behavior and is a continuous effort, which is carried out by people for life, health and welfare (11).

Self-care hemodialysis patients would have greater illness coherence, personal and treatment control (12). The purpose of self-care activities is to create or sustain the factors necessary for the growth and promotion of health, including preventing, relieving pain, treating or controlling illness and life-threatening conditions with health (13). The self-care may be affected by psychosocial factors such as anxiety, depression, life events, stressors and social support (14). On the other hand, hemodialysis patients have little knowledge about self-care, poor selfcare and disability (15). Research in this field is necessary, not only because of the continuous dependence of patients on hemodialysis and nursing care, but also due to the complex, diverse and distinctive aspects of hemodialysis (16). Although previous studies looked at self-care in CRF patients, there is very little information about self-care in hemodialysis patients (17). According to studies, the patients undergoing hemodialysis are experiencing mental problems, including stress and anxiety. Determining the correlation between patient self-care and these two important variables can be a step toward improving disease management and promoting the health of patients.

\section{Objectives}

This study aimed to determine the correlation of stress and anxiety with self-care in hemodialysis patients.
Patients and Methods

\section{Study design}

The current descriptive, cross-sectional and applied study was conducted on 80 dialysis patients who were selected by convenience sampling method, referring to the hemodialysis department at Kosar hospital in Semnan (Iran) in 2017.

\section{Inclusion criteria}

Inclusion criteria were age over 18 years of age, history of hemodialysis for at least three months and the patient's ability to collaborate or provide information.

\section{Exclusion criteria}

Exclusion criteria were the presence of physical or mental disabilities, a history of mental illness or admission to a psychiatric ward.

\section{Study questionnaires}

Data collection tools included self-care by hemodialysis patients' self-care measurement scale, Spielberger StateTrait Anxiety Inventory (STAI) and perceived stress scale (PSS) questionnaire. After obtaining patient's consent, their demographic information, including age, gender, marital status, educational level, hemodialysis per month, occupational status, comorbidities (diabetes, hypertension, heart disease, hepatitis B and hepatitis C), use of sedative medications and history of admission to the psychiatric ward and the recent experience of the stressful event, were asked by the researcher and recorded in a relevant questionnaire. Then, the questionnaires used in this study were completed by the patient or by the researcher through the interview.

Self-care was measured on the basis of self-care questionnaire in hemodialysis patients, which included 29 self-care activities related to diet and fluid control, skin and fistula care, activity and fatigue, sleep and rest, and self-care activities to reduce depression. The answers on Likert scale are graded from never to always. Points were given between zero and four to each item. The total score of this tool is between 0 and 116 . The score obtained from this standardized tool is converted into numbers between 0 and 100, and the self-care function is divided into three levels: poor, moderate and good. The validity and reliability of this questionnaire was confirmed (18).

In this study, the anxiety was measured using the STAI questionnaire, which is used in clinical research and activities. This questionnaire measures the anxiety components as the state and trait. Each of these scales has 20 items, which are scored as a four-point Likert scale. The scores of each of the two scales range from 20 to 80 and the total score of the tool is between 40 and 160 . The obtained total scores are in one of the three groups of mild anxiety (40-79), moderate anxiety (80-119) and severe anxiety (120-160) (19,20). Validity and reliability of the Spielberger Anxiety Inventory was confirmed in 
previous studies (21).

Likewise, stress was measured by perceived stress questionnaire. The questionnaire assesses the amount of person's feelings and thoughts in relation to events and situations that occurred during the past month. The perceived stress questionnaire consists of 14 questions, in which seven are positive and seven are negative. The negative factor evaluates the lack of control and negative emotional reactions, while the positive factor evaluates the level of ability to cope with external stress during the past month. Each question is evaluated on a five-point scale. The scores range from zero to four on the Likert scale, while responses are categorized as zero (never), one (seldom), two (sometimes), three (very often) and four (always). The questionnaire also includes reverse scores consisting of questions $10,9,7,6,5,4$, and 13 . Overall, the scores range from zero to 56 . The scores less than 28 are in the lower perceived stress group, and the scores equal to or greater than 28 are in the perceived stress group. Validity and reliability of the perceived stress tool was also confirmed (22).

\section{Ethical issues}

The study was in accordance with the Declaration of Helsinki and its later amendments. Additionally, the study was approved by the ethics committee affiliated with the Semnan University of Medical Sciences (\#IR.SEMUMS. REC.1395.217). All the participants were informed about the study aims and procedures. Written informed consent was obtained obtained from all the patients. This study was extracted from the general physician thesis of Maryam Zibaei, at the Semnan University of Medical Sciences.

\section{Statistical analysis}

The data were analyzed by SPSS version 23.0 using Shapiro-Wilk, Mann-Whitney, Pearson correlation, Spearman correlation, partial correlation coefficient at a significance level of 5\%. At first, the self-care score and its subscales were calculated to be 100 , and then the analysis was performed.

\section{Results}

\section{Sample characteristics}

In this study, 80 hemodialysis patients in Semnan were enrolled. The patients' status was evaluated in terms of anxiety, perceived stress, self-care and their correlation. We found, $53.1 \%$ of patients were male; $61.3 \%$ of patients were 60 years of age or older; $91.3 \%$ were married; $27.5 \%$ had educational level of high school or higher. The history of hemodialysis was less than one year in $23.8 \%$, between one and 5 years in $50 \%$ and more than 5 years in $26.2 \%$. The hypertension was observed in $65 \%$ of patients, diabetes in $50 \%$ of patients, and ischemic heart disease in $30 \%$ of patients. Moreover, $17.5 \%$ of patients used sedative medications. One patient (1.3\%) had hepatitis $\mathrm{C}$ and three
(3.8\%) had hepatitis B.

\section{Outcomes}

The mean anxiety was $83.5 \pm 18.4$ (out of 160 ). The median anxiety score was 82 . The lowest and highest scores were 48 and 122, respectively. Additionally, 46.2\% $(n=37)$ had mild anxiety (40-79), 50\% $(\mathrm{n}=40)$ had moderate anxiety (80-119) and 3.8\% ( $n=3)$ had severe anxiety (120-160). Linear regression analysis was performed to investigate the co-effect of the mentioned variables on patient anxiety. The results showed a positive and significant correlation between the use of sedative medications and anxiety scores ( $P=0.004$; linear regression analysis). The gender variable was excluded from the model and showed no significant effect (Table 1).

The mean perceived stress in the patients was $24.6 \pm 9.4$ (out of 56), 62.5\% had low perceived stress ( $<28$ ) and $37.5 \%$ had high perceived stress $(\geq 28)$. The co-effect of the above variables on perceived stress score was investigated using linear regression analysis. Among the above-mentioned variables, the results showed that only educational level had a significant negative correlation $(P=0.014$; linear regression analysis) and the use of sedative medications had a significant positive correlation $(P=0.005$; linear regression analysis) with perceived stress score, while the variable of gender was excluded from the model (Table 2).

The mean self-care score was $60.5 \pm 9.5$ (out of 100), with the median of 59.5 (from 41.4 to 84.5 ). None of the patients had poor self-care (score less than 33 ). The selfcare was moderate in 75\% (33-66) and good in 25\% (score above 66). The linear regression analysis was performed to investigate the co-effect of the variables mentioned with the self-care. The results showed that only the educational level had a positive and significant correlation with the self-care score ( $P=0.001$; linear regression analysis) while the age variable was excluded from the model (Table 3 ). Table 4 presents the mean \pm SD of anxiety, perceived stress and self-care in hemodialysis patients. By eliminating the effect of educational level, a negative and significant correlation between perceived stress score and self-care score $(P=0.001, \mathrm{r}=-0.376$; partial correlation coefficient) was detected, however the correlation between anxiety and self-care was not significant $(P=0.089, \mathrm{r}=-0.193$; partial correlation coefficient) (Table 5 ). After eliminating the effect of income level, a significant negative correlation between the stress score and the subscale of activity and fatigue was detected $(\mathrm{r}=-0.428, P=0.001$ partial correlation coefficient), and with reduced depression subscale $\quad(r=-0.547, \quad P<0.001$ partial correlation coefficient), but not significant with other subscales (Table 6). After eliminating the effect of income level, a significant negative correlation between the anxiety score and the subscale of activity and fatigue $(r=-0.316$, $P=0.005$ partial correlation coefficient test), and also with the subscale of reduced depression $(\mathrm{r}=-0.420, P<0.001$ 
Table 1. Mean, SD and distribution anxiety score in hemodialysis patients of Semnan (2017)

\begin{tabular}{|c|c|c|c|c|c|c|c|c|c|}
\hline \multirow{2}{*}{ Patient's characteristics } & \multirow{2}{*}{$\mathbf{N}$} & \multirow{2}{*}{$\%$} & \multicolumn{5}{|c|}{ Anxiety } & \multirow{2}{*}{$\mathbf{r}$} & \multirow{2}{*}{$P$ value } \\
\hline & & & Mean & SD & $40-79$ & $80-119$ & $120-160$ & & \\
\hline Geder & & & & & & & & - & 0.038 \\
\hline Female & 39 & 48.8 & 87.9 & 18.6 & $16(41.0)^{*}$ & $21(53.8)$ & $2(5.1)$ & & \\
\hline Male & 41 & 51.3 & 79.4 & 17.3 & $21(51.2)$ & $19(46.2)$ & $1(2.4)$ & & \\
\hline Age (y) & & & & & & & & 0.150 & 0.186 \\
\hline$<50$ & 17 & 21.3 & 77.2 & 14.7 & $12(70.6)$ & $5(29.4)$ & $0(0)$ & & \\
\hline $50-59$ & 14 & 17.5 & 85.1 & 18.7 & $7(50.0)$ & $6(42.9)$ & $1(7.1)$ & & \\
\hline $60-69$ & 25 & 31.3 & 84.4 & 20.4 & $9(36.0)$ & $15(60.0)$ & $1(4.0)$ & & \\
\hline$\geq 70$ & 24 & 30.0 & 78.4 & 18.4 & $9(37.5)$ & $14(58.3)$ & $1(4.2)$ & & \\
\hline Marital status & & & & & & & & - & 0.277 \\
\hline Married & 73 & 91.3 & 84.2 & 18.5 & $33(45.2)$ & $37(50.7)$ & $3(4.1)$ & & \\
\hline And so on & 7 & 8.8 & 76.3 & 16.5 & $4(57.1)$ & $3(42.9)$ & $0(0)$ & & \\
\hline Educational level & & & & & & & & -0.009 & 0.384 \\
\hline Illiterate & 15 & 18.8 & 84.5 & 22.6 & $7(46.7)$ & $7(46.7)$ & $1(6.7)$ & & \\
\hline Primary school & 31 & 38.8 & 84.7 & 17.5 & $14(45.2)$ & $15(48.4)$ & $2(6.5)$ & & \\
\hline Secondary school & 12 & 15.0 & 87.9 & 18.9 & $4(33.3)$ & $8(66.7)$ & $0(0)$ & & \\
\hline High school or higher & 22 & 27.5 & 78.8 & 16.3 & $12(54.5)$ & $10(45.5)$ & $0(0)$ & & \\
\hline Duration of hemodialysis $(\mathrm{y})$ & & & & & & & & 0.015 & 0.898 \\
\hline$<1$ & 19 & 23.8 & 86.8 & 19.2 & $7(36.8)$ & $11(57.9)$ & $1(5.3)$ & & \\
\hline $1-5$ & 40 & 50.0 & 80.1 & 18.6 & $23(57.5)$ & $16(40.0)$ & $1(2.5)$ & & \\
\hline$>5$ & 21 & 26.2 & 87.0 & 16.8 & $7(33.3)$ & $13(61.9)$ & $1(4.8)$ & & \\
\hline HTN & & & & & & & & - & 0.880 \\
\hline Yes & 52 & 65.0 & 83.3 & 19.7 & $26(50.0)$ & $24(46.2)$ & $2(3.8)$ & & \\
\hline No & 28 & 35.0 & 84.0 & 16.1 & $11(39.3)$ & $16(57.1)$ & $1(3.6)$ & & \\
\hline DM & & & & & & & & - & 0.337 \\
\hline Yes & 40 & 50.0 & 85.5 & 20.1 & $17(42.5)$ & $21(52.5)$ & $2(5.0)$ & & \\
\hline No & 40 & 50.0 & 81.5 & 16.4 & $20(50.0)$ & $19(47.5)$ & $1(2.5)$ & & \\
\hline IHD & & & & & & & & - & 0.131 \\
\hline Yes & 24 & 30.0 & 88.3 & 19.8 & $7(29.2)$ & $15(62.5)$ & $2(8.3)$ & & \\
\hline No & 56 & 70.0 & 81.5 & 17.5 & $30(53.6)$ & $25(44.6)$ & $1(1.8)$ & & \\
\hline Usage of sedative & & & & & & & & - & 0.004 \\
\hline Yes & 14 & 17.5 & 96.3 & 14.5 & $3(21.4)$ & $11(78.6)$ & $0(0)$ & & \\
\hline No & 66 & 82.5 & 80.8 & 18.1 & $34(51.5)$ & $29(43.9)$ & $3(4.5)$ & & \\
\hline
\end{tabular}

SD, standard deviation; HTN, hypertension; DM, diabetes mellitus; IHD, ischemic heart disease; * No. (\%).

partial correlation coefficient test) was found, but with other subscales was not significant (Table 7).

\section{Discussion}

In this study, whose aim was to investigate the relationship between stress and anxiety with self-care in hemodialysis patients in the Kosar hospital of Semnan, 80 patients were evaluated. The highest level of anxiety (50\%) was related to moderate anxiety. In line with the results of this study, Subramanian et al reported that the most frequent anxiety level was moderate in the hemodialysis patients (23). Another study indicated high prevalence of anxiety (7). Musa et al exhibited that the patients undergoing hemodialysis had severe anxiety that was inconsistent with the present study (24). In the study of Vasilopoulou et al, most of hemodialysis patients had severe anxiety, which did not conform with our study (25). This difference can be due to cultural, social, psychological and familial differences in hemodialysis patients, which has an effect on their anxiety level.

In this study, $62.5 \%$ of the patients had low perceived stress $(<28)$ and $37.5 \%$ had high perceived stress $(\geq 28)$. Hmwe et al in Malaysia, reported that more than one third of hemodialysis patients (35.2\%) had symptoms of stress, $20.4 \%$ had mild stress, $10.2 \%$ had moderate and $1.9 \%$ had severe and $2.8 \%$ had very severe stress (23). Gemmell et al underlined that the hemodialysis patients were more affected by psychosocial stressors than physiological ones, because the use of religious habits was the most common strategy for coping with perceived stress (26). Differences in the factors of stress and coping methods are effective on the level of perceived stress. 
Table 2. Mean, SD and distribution perceived stress score in hemodialysis patients of Semnan (2017)

\begin{tabular}{|c|c|c|c|c|c|c|}
\hline \multirow{2}{*}{ Patient's characteristics } & \multicolumn{4}{|c|}{ Perceived stress } & \multirow{2}{*}{$\mathbf{r}$} & \multirow{2}{*}{$P$ value } \\
\hline & Mean & SD & Low $(<28)$ & High ( $\geq 28)$ & & \\
\hline \multicolumn{7}{|l|}{ Geder } \\
\hline Female & 27.4 & 9.5 & $21(53.8)^{*}$ & $18(46.2)$ & \multirow[t]{2}{*}{-} & \multirow[t]{2}{*}{0.011} \\
\hline Male & 22.0 & 8.8 & $29(70.7)$ & $12(29.3)$ & & \\
\hline \multicolumn{7}{|l|}{ Age (y) } \\
\hline$<50$ & 22.7 & 9.5 & $13(76.5)$ & $4(23.5)$ & \multirow{4}{*}{0.084} & \multirow{4}{*}{0.459} \\
\hline $50-59$ & 25.9 & 8.1 & $9(64.3)$ & $5(35.7)$ & & \\
\hline $60-69$ & 24.1 & 11.1 & $14(56.0)$ & $11(44.0)$ & & \\
\hline$\geq 70$ & 25.8 & 8.6 & $14(58.3)$ & $10(41.7)$ & & \\
\hline \multicolumn{7}{|l|}{ Marital status } \\
\hline Married & 24.7 & 9.0 & $46(83.0)$ & $27(37.0)$ & \multirow[t]{2}{*}{-} & \multirow[t]{2}{*}{0.697} \\
\hline etc & 23.3 & 14.2 & $4(57.1)$ & $3(42.9)$ & & \\
\hline \multicolumn{7}{|l|}{ Educational level } \\
\hline Illiterate & 26.1 & 9.6 & $9(60.0)$ & $6(40.0)$ & \multirow{4}{*}{-0.272} & \multirow{4}{*}{0.014} \\
\hline Primary school & 27.4 & 10.2 & $15(48.4)$ & $16(51.6)$ & & \\
\hline Secondary school & 23.3 & 8.3 & $8(66.7)$ & $4(33.3)$ & & \\
\hline High school or higher & 20.3 & 7.6 & $18(81.8)$ & $4(18.2)$ & & \\
\hline \multicolumn{7}{|c|}{ Duration of hemodialysis (y) } \\
\hline$<1$ & 26.6 & 8.0 & $11(57.9)$ & $8(41.2)$ & \multirow{3}{*}{-0.023} & \multirow{3}{*}{0.838} \\
\hline $1-5$ & 23.0 & 9.7 & $26(65.0)$ & $14(35.0)$ & & \\
\hline$>5$ & 26.0 & 10.0 & 13 (61.9) & $8(38.1)$ & & \\
\hline \multicolumn{7}{|l|}{ HTN } \\
\hline Yes & 23.9 & 9.7 & $34(65.4)$ & $18(34.6)$ & \multirow[t]{2}{*}{-} & \multirow[t]{2}{*}{0.382} \\
\hline No & 25.9 & 9.0 & $16(57.1)$ & $12(42.9)$ & & \\
\hline \multicolumn{7}{|l|}{ DM } \\
\hline Yes & 24.4 & 10.5 & $25(62.5)$ & $15(37.5)$ & \multirow[t]{2}{*}{-} & \multirow[t]{2}{*}{0.851} \\
\hline No & 24.8 & 8.4 & $25(62.5)$ & $15(37.5)$ & & \\
\hline \multicolumn{7}{|l|}{ IHD } \\
\hline Yes & 25.2 & 11.0 & $15(62.5)$ & $9(37.5)$ & \multirow[t]{2}{*}{-} & \multirow[t]{2}{*}{0.720} \\
\hline No & 24.4 & 8.8 & $35(62.5)$ & $21(37.5)$ & & \\
\hline \multicolumn{7}{|l|}{ Usage of sedative } \\
\hline Yes & 30.9 & 6.8 & $5(35.7)$ & $9(64.3)$ & - & 0.005 \\
\hline No & 23.3 & 9.4 & $45(68.2)$ & $21(31.8)$ & & \\
\hline
\end{tabular}

SD, standard deviation; HTN, hypertension; DM, diabetes mellitus; IHD, ischemic heart disease; * No. (\%).

In this study, the mean self-care score of patients was $60.5 \pm 9.5$ (out of 100) and the highest score was related to moderate self-care, which is consistent with a study of Mollaoglu et al with a mean self-care score of $62.50 \pm 12.20$ (14). Our results are consistent with a study of Tsay and Healstead in Taiwan with the moderate self-care activity of these patients (27). The results of Song et al also showed that the highest self-care level was moderate (28). The self-care is considered as a monitoring function, different from other human regulatory functions such as neuroendocrine. It needs to be learned and must be performed consciously and continuously in accordance with the regulatory requirements of individuals. Therefore, appropriate training programs on the disease, therapeutic methods and those that should be followed by the patient under self-care improve physical function, general health and emotional, mental and social status of patients (28).

By eliminating the effect of educational level in this study, a significant negative correlation between self-care and perceived stress was seen, which is consistent with the study by Kammerer et al in the United States. They also reported that the stress had a negative impact on self-care, since more stress reduces the self-care efficacy (29). After eliminating the effect of income level in this study, there was a significant negative correlation between the stress score and the subscales of activity, fatigue and reduced depression, however the correlation was not significant with other subscales. No similar studies have been conducted on the relationship between self-care and stress sub-dimensions. This finding implies the need for future studies. Moreover, after eliminating the effect of educational level in this study, no significant correlation 
Table 3. Mean, SD and distribution self-care score in hemodialysis patients of Semnan (2017)

\begin{tabular}{|c|c|c|c|c|c|c|}
\hline \multirow{2}{*}{ Patient's Characteristics } & \multicolumn{4}{|c|}{ Self-care } & \multirow{2}{*}{$\mathbf{r}$} & \multirow{2}{*}{$P$ value } \\
\hline & Mean & SD & $33-66$ & $>66$ & & \\
\hline \multicolumn{7}{|l|}{ Geder } \\
\hline Female & 60.1 & 9.8 & $31(79.6)^{*}$ & $8(20.5)$ & - & 0.720 \\
\hline Male & 60.9 & 9.4 & $29(70.7)$ & $12(29.3)$ & & \\
\hline \multicolumn{7}{|l|}{ Age (y) } \\
\hline$<50$ & 64.1 & 9.2 & $10(58.8)$ & $7(41.2)$ & & \\
\hline $50-59$ & 60.1 & 7.8 & $13(92.9)$ & $1(7.1)$ & -0.237 & -0.035 \\
\hline $60-69$ & 60.2 & 10.1 & $17(68.0)$ & $8(32.0)$ & & \\
\hline$\geq 70$ & 9.8 & 9.8 & $20(83.3)$ & $4(16.7)$ & & \\
\hline \multicolumn{7}{|l|}{ Marital status } \\
\hline Married & 60.0 & 9.6 & $56(76.7)$ & $17(23.3)$ & - & 0.135 \\
\hline etc & 65.6 & 7.5 & $4(57.1)$ & $3(42.9)$ & & \\
\hline \multicolumn{7}{|l|}{ Educational level } \\
\hline Illiterate & 55.6 & 5.9 & $15(100)$ & $0(0)$ & & \\
\hline Primary school & 58.0 & 9.7 & $25(80.6)$ & $6(19.4)$ & 0.409 & $<0.001$ \\
\hline Secondary school & 65.2 & 8.0 & $6(50.0)$ & $6(50.0)$ & & \\
\hline High school or higher & 64.8 & 9.6 & $14(63.6)$ & $8(36.4)$ & & \\
\hline \multicolumn{7}{|c|}{ Duration of hemodialysis (y) } \\
\hline$<1$ & 58.3 & 9.9 & $16(84.2)$ & $3(15.8)$ & & \\
\hline $1-5$ & 60.4 & 9.3 & $32(80.0)$ & $8(20.0)$ & 0.173 & 0.126 \\
\hline$>5$ & 62.7 & 9.7 & $12(57.1)$ & $9(42.9)$ & & \\
\hline \multicolumn{7}{|l|}{ HTN } \\
\hline Yes & 59.5 & 9.3 & $40(76.9)$ & $12(23.1)$ & - & 0.220 \\
\hline No & 62.3 & 9.8 & $20(71.4)$ & $8(28.6)$ & & \\
\hline \multicolumn{7}{|l|}{ DM } \\
\hline Yes & 59.7 & 10.0 & $32(80.0)$ & $8(20.0)$ & - & 0.445 \\
\hline No & 61.3 & 9.1 & $28(70.0)$ & $12(30.0)$ & & \\
\hline \multicolumn{7}{|l|}{ IHD } \\
\hline Yes & 57.9 & 9.3 & $19(79.2)$ & $5(20.8)$ & - & 0.111 \\
\hline No & 61.6 & 9.5 & $41(73.2)$ & $15(26.8)$ & & \\
\hline \multicolumn{7}{|l|}{ Usage of sedative } \\
\hline Yes & 62.0 & 9.5 & $10(71.4)$ & $4(28.6)$ & - & 0.816 \\
\hline No & 60.2 & 9.6 & $50(75.8)$ & $16(24.2)$ & & \\
\hline
\end{tabular}

SD, standard deviation; HTN, hypertension; DM, diabetes mellitus; IHD, ischemic heart disease; * No. (\%). Note. Because of absence of the score lower than $33,<33$ column is deleted

between self-care and anxiety in hemodialysis patients was detected. In the study of Mollaoglu et al, self-care had a negative and significant correlation with anxiety, which

Table 4. Mean, SD of self-care, perceived stress and anxiety in hemodialysis patients of Semnan (2017)

\begin{tabular}{llll}
\hline Patient's characteristics & $\%$ & Mean & SD \\
\hline Mild anxiety & 46.2 & & \\
Moderate anxiety & 50 & 83.5 & 18.4 \\
Severe anxiety & 3.8 & & \\
Low stress & 62.5 & & \\
High stress & 37.5 & 24.6 & 9.4 \\
Moderate self-care & 75 & & \\
Good self-care & 25 & 60.5 & 9.5 \\
\hline
\end{tabular}

SD: standard deviation.

Note. Because of absence of the weak self-care, the weal self-care is deleted. is inconsistent with our study (14). This difference can be due to the sample size and tools.

\section{Conclusion}

The results of this study showed, the correlation between perceived stress and self-care, which can be effective in improving the general health of hemodialysis patients, proper management of illness by patients, and reduction of complications and mortality rates. In order to manage the course of the disease, it seems that physicians should concentrate on the importance of treating stress in hemodialysis patients.

\section{Limitations of the study}

Answering the questions of the questionnaires sometimes causes fatigue in hemodialysis patients, which is resolved by considering rest periods during hemodialysis. It is recommended to investigate the correlation between 
Table 5. Mean, SD and distribution self-care score in different levels of the anxiety and perceived stress in hemodialysis patients of Semnan (2017)

\begin{tabular}{|c|c|c|c|c|c|c|c|c|}
\hline \multirow{2}{*}{ Patient's characteristics } & \multirow{2}{*}{$\mathbf{N}$} & \multirow{2}{*}{$\%$} & \multicolumn{4}{|c|}{ Self-care } & \multirow{2}{*}{$r$} & \multirow{2}{*}{$P$ value } \\
\hline & & & Mean & SD & Moderate 33-66 & Good >66 & & \\
\hline Mild anxiety (40-79) & 37 & 46.2 & 61.7 & 6.7 & $28(75.7) *$ & $9(24.3)$ & & \\
\hline Moderate anxiety (80-119) & 40 & 50.0 & 60.5 & 11.1 & $29(72.5)$ & $11(27.5)$ & -0.193 & 0.089 \\
\hline Severe anxiety (120-160) & 3 & 3.8 & 46.0 & 2.2 & $3(100)$ & $0(0)$ & & \\
\hline \multicolumn{9}{|l|}{ Perceived stress } \\
\hline Low $(<28)$ & 50 & 62.5 & 63.3 & 9.2 & $34(68.0)$ & $16(32.0)$ & -0.376 & 0.001 \\
\hline High ( $\geq 28)$ & 30 & 37.5 & 55.9 & 8.3 & $26(86.7)$ & $4(13.3)$ & & \\
\hline
\end{tabular}

SD, standard deviation; * No. (\%).

Note. Because of absence of the score lower than $33,<33$ column is deleted

Table 6. Mean, SD and frequency distribution of self-care subscales in different levels of perceived stress in hemodialysis patients of Semnan (2017)

\begin{tabular}{|c|c|c|c|c|c|c|c|c|}
\hline \multirow{2}{*}{ Self-care subscale } & \multirow{2}{*}{ Perceived stress } & \multirow{2}{*}{ Mean } & \multirow{2}{*}{ SD } & \multicolumn{3}{|c|}{ Self-care } & \multirow{2}{*}{$\mathbf{r}$} & \multirow{2}{*}{$P$ value } \\
\hline & & & & $<33$ & $33-66$ & $>66$ & & \\
\hline \multirow{2}{*}{ Nutrition and Diet therapy } & $<28$ & 82.4 & 16.1 & $1(2)^{*}$ & $5(10)$ & $44(88)$ & \multirow{2}{*}{0.021} & \multirow{2}{*}{0.853} \\
\hline & $\geq 28$ & 84.5 & 14.6 & $0(0)$ & $5(16.7)$ & $25(83.3)$ & & \\
\hline \multirow{2}{*}{ Skin and Fistula care } & $<28$ & 66.5 & 12.0 & $0(0)$ & $28(56)$ & $22(44)$ & \multirow{2}{*}{-0.070} & \multirow{2}{*}{0.541} \\
\hline & $\geq 28$ & 63.1 & 11.3 & $0(0)$ & $17(56.7)$ & $13(43.3)$ & & \\
\hline \multirow{2}{*}{ Activity and Fatigue } & $<28$ & 47.8 & 25.7 & $10(20)$ & $27(54)$ & $13(26)$ & \multirow{2}{*}{-0.428} & \multirow{2}{*}{$<0.001$} \\
\hline & $\geq 28$ & 23.9 & 24.9 & $22(73.3)$ & $3(10)$ & $5(16.7)$ & & \\
\hline \multirow{2}{*}{ Sleep and Rest } & $<28$ & 29.2 & 19.6 & $34(68)$ & $15(30)$ & $1(2)$ & \multirow{2}{*}{-0.135} & \multirow{2}{*}{0.234} \\
\hline & $\geq 28$ & 23.1 & 17.7 & $24(80)$ & $6(20)$ & $0(0)$ & & \\
\hline \multirow{2}{*}{ Reduced Depression } & $<28$ & 66.5 & 16.9 & $2(4)$ & $21(42)$ & $27(54)$ & \multirow{2}{*}{-0.547} & \multirow{2}{*}{$<0.001$} \\
\hline & $\geq 28$ & 46.7 & 15.3 & $6(20)$ & $20(66.7)$ & $4(13.3)$ & & \\
\hline \multirow{2}{*}{ Total Self-care } & $<28$ & 63.3 & 9.2 & $0(0)$ & $34(48)$ & $16(32)$ & \multirow{2}{*}{-0.376} & \multirow{2}{*}{0.001} \\
\hline & $\geq 28$ & 55.9 & 8.3 & $0(0)$ & $26(86.7)$ & $4(13.3)$ & & \\
\hline
\end{tabular}

SD, standard deviation; * No. (\%).

Table 7. Mean, SD and frequency distribution of Self-care subscales in different levels of Anxiety in hemodialysis patients of Semnan (2017)

\begin{tabular}{|c|c|c|c|c|c|c|c|c|}
\hline \multirow{2}{*}{ Self-care subscale } & \multirow{2}{*}{ Anxiety } & \multirow{2}{*}{ Mean } & \multirow{2}{*}{ SD } & \multicolumn{3}{|c|}{ Self-care level } & \multirow{2}{*}{$\mathbf{r}$} & \multirow{2}{*}{$P$ value } \\
\hline & & & & $<33$ & $33-66$ & $>66$ & & \\
\hline \multirow{3}{*}{ Nutrition and diet therapy } & $40-79$ & 83.9 & 13.5 & $0(0)^{*}$ & $1(2.7)$ & $36(97.3)$ & \multirow{3}{*}{-0.009} & \multirow{3}{*}{0.938} \\
\hline & 80-119 & 82.3 & 17.8 & $1(2.5)$ & $9(22.5)$ & $30(75)$ & & \\
\hline & $120-160$ & 86.9 & 4.1 & $0(0)$ & $0(0)$ & $3(100)$ & & \\
\hline \multirow{3}{*}{ Skin and fistula care } & $40-79$ & 62.4 & 7.3 & $0(0)$ & $26(70.3)$ & $11(9.7)$ & \multirow{3}{*}{0.094} & \multirow{3}{*}{0.411} \\
\hline & $80-119$ & 68.9 & 13.9 & $0(0)$ & $16(40)$ & $24(60)$ & & \\
\hline & $120-160$ & 50.8 & 3.8 & $0(0)$ & $3(100)$ & $0(0)$ & & \\
\hline \multirow{3}{*}{ Activity and fatigue } & $40-79$ & 46.6 & 25.3 & $8(21.6)$ & $18(48.6)$ & $11(29.7)$ & \multirow{3}{*}{-0.316} & \multirow{3}{*}{0.005} \\
\hline & $80-119$ & 33.5 & 28.8 & $21(52.5)$ & $12(30)$ & 7 (17.5) & & \\
\hline & $120-160$ & 13.9 & 12.7 & $3(100)$ & $0(0)$ & $0(0)$ & & \\
\hline \multirow{3}{*}{ Sleep and rest } & $40-79$ & 25.5 & 15.5 & $29(78.4)$ & $8(21.6)$ & $0(0)$ & \multirow{3}{*}{0.020} & \multirow{3}{*}{0.860} \\
\hline & 80-119 & 29.8 & 21.5 & $26(65)$ & $13(32.5)$ & $1(2.5)$ & & \\
\hline & $120-160$ & 6.2 & 6.2 & $3(100)$ & $0(0)$ & $0(0)$ & & \\
\hline \multirow{3}{*}{ Reduced depression } & $40-79$ & 67.2 & 16.4 & $1(2.7)$ & $14(37.8)$ & $22(59.5)$ & \multirow{3}{*}{-0.420} & \multirow{3}{*}{$<0.001$} \\
\hline & 80-119 & 53.7 & 17.5 & $5(12.5)$ & $26(65)$ & $9(22.5)$ & & \\
\hline & $120-160$ & 30.0 & 15.0 & $2(66.7)$ & $1(33.3)$ & $0(0)$ & & \\
\hline \multirow{3}{*}{ Total self-care } & $40-79$ & 61.7 & 6.7 & $0(0)$ & $28(75.7)$ & $9(24.3)$ & \multirow{3}{*}{-0.193} & \multirow{3}{*}{0.089} \\
\hline & $80-119$ & 60.5 & 11.1 & $0(0)$ & $29(72.5)$ & $11(27.5)$ & & \\
\hline & $120-160$ & 46.0 & 2.2 & $0(0)$ & $3(100)$ & $0(0)$ & & \\
\hline
\end{tabular}


anxiety and self-care with a larger sample size of patients undergoing hemodialysis, the stressors in hemodialysis patients and their control strategies.

\section{Acknowledgments}

We would like to express our gratitude to the Research and Technology Deputy of Semnan University of Medical Sciences and relevant authorities for their financial and moral support of this study (Grant \# 1192) and we would like to thank the Social Determinants of Health Research Center. Also we would like to show our appreciation to all the participating hemodialysis patients.

\section{Authors' contribution}

MZ: Study conception/design; data collection; drafting of manuscript. MN: Study conception/design, data collection/analysis; drafting of manuscript; critical revisions for important intellectual content; supervision. RG: Study conception/design, data analysis; drafting of manuscript.

\section{Conflicts of interest}

The authors declared no competing interests.

\section{Ethical considerations}

Ethical issues (including plagiarism, misconduct, data fabrication, falsification, double publication or submission, redundancy) have been completely observed by the authors.

\section{Funding/Support}

Semnan University of Medical Sciences supported this research financially (Grant \#1192).

\section{References}

1. Longo DL, Fauci AS, Kasper D, Hauser S, Jameson J, Loscalzo J. Harrison's Principles of Internal Medicine. Vol. 2. New York: The McGraw-Hill: 2012. doi:10.1001/ jama.308.17.1813-b.

2. Liyanage T, Ninomiya T, Jha V, Neal B, Patrice HM, Okpechi I, et al. Worldwide access to treatment for end-stage kidney disease: a systematic review. Lancet. 2015;385:1975-82. doi.10.1016/S0140-6736(14)61601-9.

3. Turkmen K, Eedur FM, Guney I, Gaipov A, Turgut F, Altintepe L, et al. Sleep quality, depression, and quality of life in elderly hemodialysis patients. Int J Nephrol Renovasc Dis. 2012;5:135-42. doi: 10.2147/IJNRD.S36493.

4. Esther Mok B. Stressors and coping methods among chronic haemodialysis patients in Hong Kong. J Clin Nurs. 2001;10:1-10. doi: 10.1046/j.1365-2702.2001.00500.x.

5. Tchape ODM, Tchapoga YB, Atuhaire C, Priebe G, Cumber SN. Physiological and psychosocial stressors among hemodialysis patients in the Buea Regional Hospital, Cameroon. Pan Afr Med J. 2018;30:49. doi: 10.11604/ pamj.2018.30.49.15180.

6. Turkistani I, Nuqali A, Badawi M, Taibah O, Alserihy $\mathrm{O}$, Morad $\mathrm{M}$, et al. The prevalence of anxiety and depression among end-stage renal disease patients on hemodialysis in Saudi Arabia. Ren Fail. 2014;36:1510-5. doi: $10.3109 / 0886022 \mathrm{X}$.

7. Feroze U, Martin D, Kalantar-Zadeh K, Kim JC, ReinaPatton A, Kopple JD. Anxiety and depression in maintenance dialysis patients: preliminary data of a cross-sectional study and brief literature review. J Renal Nutr. 2012;22:207-10. doi: 10.1053/j.jrn.2011.10.009.

8. El Filali A, Bentata Y, Ada N, Oneib B. Depression and anxiety disorders in chronic hemodialysis patients and their quality of life: a cross-sectional study about 106 cases in the northeast of Morocco. Saudi J Kidney Dis Transpl. 2017;28:341. doi: 10.4103/1319-2442.202785.

9. Welch JL, Austin JK. Stressors, coping and depression in haemodialysis patients. J Adv Nurs. 2001;33:200-7.doi. 10.1046/j.1365-2648.2001.01654.x.

10. Yurtkuran M, Alp A, Dilek K. A modified yoga-based exercise program in hemodialysis patients: a randomized controlled study. Complement Ther Med. 2007;15:164-71. doi: $10.1016 /$ j.ctim.2006.06.008.

11. Wu SFV, Hsieh NC, Lin LJ, Tsai JM. Prediction of self-care behaviour on the basis of knowledge about chronic kidney disease using self-efficacy as a mediator. J Clin Nurs. 2016;25:2609-18. doi: 10.1111/jocn.13305.

12. Jayanti A, Foden P, Wearden A, Mitra S. Illness beliefs in end stage renal disease and associations with self-care modality choice. PloS One. 2016;11:e0154299. doi: 10.1371/ journal.pone.0154299.

13. Meleis A. Nursing Theories. 4th ed. Philadelphia: Lippincot Co.; 2005. p. 301-54.

14. Mollaoglu M. Perceived social support, anxiety, and self care among patients receiving hemodialysis. Dial Transplant. 2006;35:144-55. doi: 10.1002/dat.20002.

15. Wang LM, Chiou CP. Effectiveness of interactive multimedia $\mathrm{CD}$ on self-care and powerlessness in hemodialysis patients. J Nurs Res. 2011;19:102-11. doi: 10.1097/JNR.0b013e31821b0eff.

16. Martin-McDonald K. Being dialysis-dependent: a qualitative perspective. Collegian. 2003;10:29-33. doi: 10.1016/S1322-7696(08)60052-9.

17. Curtin RB, Walters BA, Schatell D, Pennell P, Wise M, Klicko K. Self-efficacy and self-management behaviors in patients with chronic kidney disease. Adv Chronic Kidney Dis. 2008;15:191-205. doi: 10.1053/j.ackd.2008.01.006.

18. Ören B, Enç N. Development and psychometric testing of the self-care agency scale for patients underrgoing longterm dialysis in Turkey. J Ren Care. 2014;40:266-73. doi: $10.1111 /$ jorc. 12098.

19. Lehrner J, Eckersberger C, Walla P, Pötsch G, Deecke L. Ambient odor of orange in a dental office reduces anxiety and improves mood in female patients. Physiol Behav. 2000;71:83-6. doi: 10.1016/S0031-9384(00)00308-5.

20. Holm L, Fitzmaurice L. Emergency department waiting room stress: can music or aromatherapy improve anxiety scores? Pediatr Emerg Care. 2008;24:836-8. doi: 10.1097/ PEC.0b013e31818ea04c.

21. Spielberger CD. STAI manual for the state-trait anxiety inventory. Self-Evaluation Questionnaire. Consulting Psychologists Press; 1970.

22. Cohen S, Kamarck T, Mermelstein R. A global measure 
of perceived stress. J Health Soc Behav. 1983:385-96. doi:10.2307/2136404.

23. Hmwe NTT, Subramanian P, Tan LP, Chong WK. The effects of acupressure on depression, anxiety and stress in patients with hemodialysis: A randomized controlled trial. Int J Nurs Stud. 2015;52:509-18. doi: 10.1016/j. ijnurstu.2014.11.002.

24. Musa AS, Pevalin DJ, Al Khalaileh MA. Spiritual wellbeing, depression, and stress among hemodialysis patients in Jordan. J Holis Nurs. 2018;36:354-65. doi: 10.1177/0898010117736686.

25. Vasilopoulou C, Bourtsi E, Giaple S, Koutelekos I, Theofilou $\mathrm{P}$, Polikandrioti $\mathrm{M}$. The impact of anxiety and depression on the quality of life of hemodialysis patients. Glob J Health Sci. 2016;8:45-55. doi: 10.5539/gjhs.v8n1p45.

26. Gemmell LA, Terhorst L, Jhamb M, Unruh M, Myaskovsky
L, Kester L, et al. Gender and racial differences in stress, coping, and health-related quality of life in chronic kidney disease. J Pain Symptom Manage. 2016;52:806-12. doi: 10.1016/j.jpainsymman.2016.05.029.

27. Tsay SL, Healstead M. Self-care self-efficacy, depression, and quality of life among patients receiving hemodialysis in Taiwan. Int J Nurs Stud. 2002;39(3):245-51. doi: 10.1016/ S0020-7489(01)00030-X.

28. Song MK, Paul S, Plantinga L, Henry C, Turberville-Trujillo L. Social networks of self-care and perceived treatment burden among patients on in-center hemodialysis. Kidney Med. 2019;1:97-103. doi: 10.1016/j.xkme.2019.04.001.

29. Kammerer J, Garry G, Hartigan M, Carter B, Erlich L. Adherence in patients on dialysis: strategies for success. Nephrol Nurs J. 2007;34:479-86

Copyright () 2020 The Author(s); Published by Nickan Research Institute. This is an open-access article distributed under the terms of the Creative Commons Attribution License (http://creativecommons.org/licenses/by/4.0), which permits unrestricted use, distribution, and reproduction in any medium, provided the original work is properly cited. 